\title{
Toxic epidermal necrolysis and
}

\section{Stevens-Johnson syndrome}

Walayat Hussain BSc MBChB MRCP, Specialist Registrar in Dermatology

Nicholas M Craven BM BCh MA FRCP, Consultant Dermatologist

Department of Dermatology, Burnley General Hospital, Burnley, Lancashire

\section{Clin Med 2005:5:555-8}

Toxic epidermal necrolysis (TEN) and Stevens-Johnson syndrome (SJS) are rare, potentially life-threatening medical emergencies, characterised by widespread epidermal loss with mucous membrane involvement. Most cases are attributable to drugs (Table 1), so knowledge of these conditions is essential for all physicians. Rarely, infections (eg Mycoplasma pneumoniae) may be responsible.

The annual incidence of TEN and SJS is $0.4-1.2$ and $1.2-6$ cases per million per year, respectively. ${ }^{1}$ Women are more fre-

\section{Key Points}

Toxic epidermal necrolysis and
Stevens-Johnson syndrome are
rare, life-threatening,
mucocutaneous adverse reactions
to drugs
Widespread epidermal loss occurs as a
result of keratinocyte apoptosis
Complications develop similar to those
seen after severe burns
Prompt drug withdrawal and
supportive care in a burns/high
dependency unit are the mainstay
of treatment

The use of steroids and other disease-modifying interventions such as intravenous immunoglobulin lacks supportive evidence from randomised controlled trials

KEY WORDS: continuing medical education, Stevens-Johnson syndrome, toxic epidermal necrolysis quently affected (1.5:1) and the incidence increases with age. ${ }^{2}$ Individuals at particular risk include 'slow acetylators', patients treated for brain neoplasms or head injury and immunocompromised patients. The risk of developing TEN is a thousand times higher in patients with HIV and AIDS than in the normal population. ${ }^{3}$ Possible explanations include the HIV infection itself, the increased number of drugs these patients receive and the altered ratio between $\mathrm{CD} 4^{+}$and CD8 ${ }^{+}$T lymphocytes. ${ }^{4}$

This article presents an overview of the aetiology, pathogenesis and clinical features of TEN and SIS and discusses the principles of management and the role of potential disease-modifying therapies.

\section{Pathogenesis}

The precise molecular basis of TEN and SIS still remains to be fully elucidated. It appears that TEN patients, who have an

Table 1. Drugs most frequently implicated in toxic epidermal necrolysis and Stevens-Johnson syndrome.

\begin{tabular}{|c|c|}
\hline \multicolumn{2}{|l|}{ Allopurinol } \\
\hline Antibiotics & $\begin{array}{l}\text { chloramphenicol } \\
\text { macrolides } \\
\text { penicillin } \\
\text { quinolones } \\
\text { sulfonamides* }\end{array}$ \\
\hline Anticonvulsants & $\begin{array}{l}\text { carbamazepine } \\
\text { lamotrigine } \\
\text { phenobarbitone } \\
\text { phenytoin } \\
\text { valproate }\end{array}$ \\
\hline NSAIDs & \\
\hline
\end{tabular}

Table 2. Cutaneous involvement in toxic epidermal necrolysis (TEN) and Stevens-Johnson syndrome (SJS).

\begin{tabular}{llcc} 
Clinical entity & TEN & SJS & SJS-TEN overlap \\
\hline Epidermal loss & $>30 \%$ & $<10 \%$ & $10-30 \%$
\end{tabular}

increased incidence of the haplotype HLA-B $12,{ }^{5}$ demonstrate an inability to detoxify intermediate reactive drug metabolites. An immune response is then mounted against the antigenic complexes formed by the interaction of these also compelling evidence that the end-point of TEN and SJS (ie epidermal necrolysis) is due to widespread apoptosis of keratinocytes. ${ }^{8}$ Cytokines such as interleukin-6, tumour necrosis factor alpha and the CD95 system (Fas ligand and Fas receptor) appear to play a role in the induction of this apoptosis ${ }^{9-11}$ and consequently have become targets for possible therapeutic interventions in TEN.

\section{Clinical features}

It is not uncommon for patients to describe a prodrome, characterised by 48-72 hours of cough, sore throat, myalgia and anorexia, before the cutaneous manifestations become apparent in TEN and SJS. Once the skin is involved, it is possible to distinguish the two conditions clinically according to the extent of cutaneous involvement (Table 2).

Skin lesions usually begin as warm, dusky-red, morbilliform macules, initially discrete but subsequently becoming confluent. The epidermis sloughs in sheets, giving rise to flaccid blisters and leaving a characteristic moist, denuded dermis (Fig 1). This process may occur within several hours or take several days. Other notable features include:

- haemorrhagic crusting of the lips (Fig 2)

- conjunctivitis

- intense pain in affected areas of skin

- fever

- genital soreness and erosions

- arthralgia

- oesophageal/tracheal involvement (rare). metabolites and host tissues. ${ }^{6,7}$ There is 


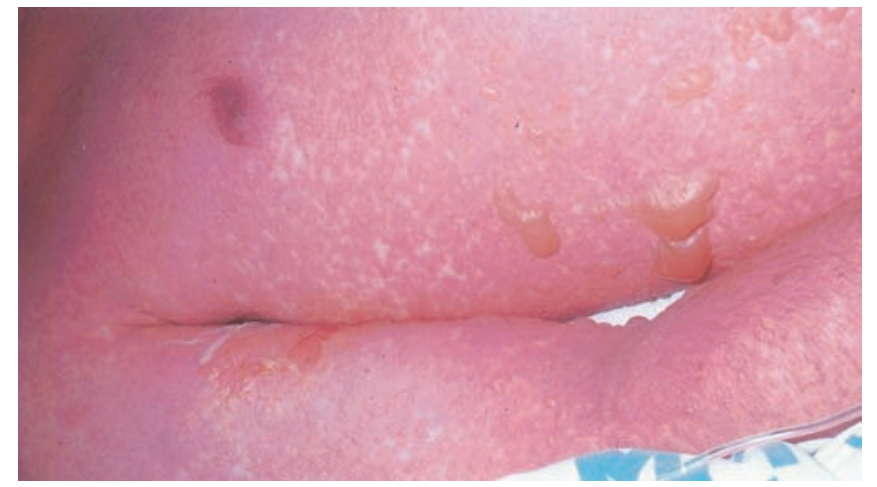

Fig 1. Acute changes of toxic epidermal necrolysis. Confluent erythematous macules over the chest and arm with areas of flaccid blistering and epidermal sloughing.

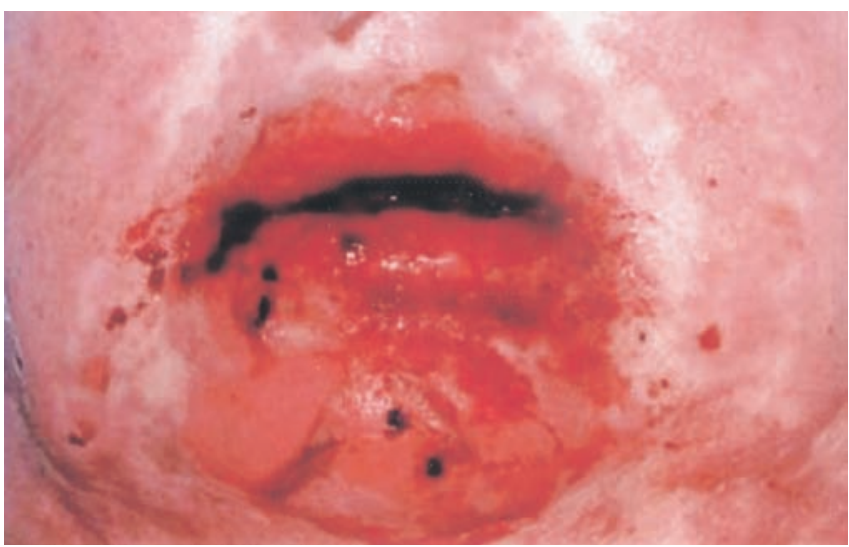

Fig 2. Mucosal involvement in toxic epidermal necrolysis. Haemorrhagic crusting and epidermal loss affecting the lips.
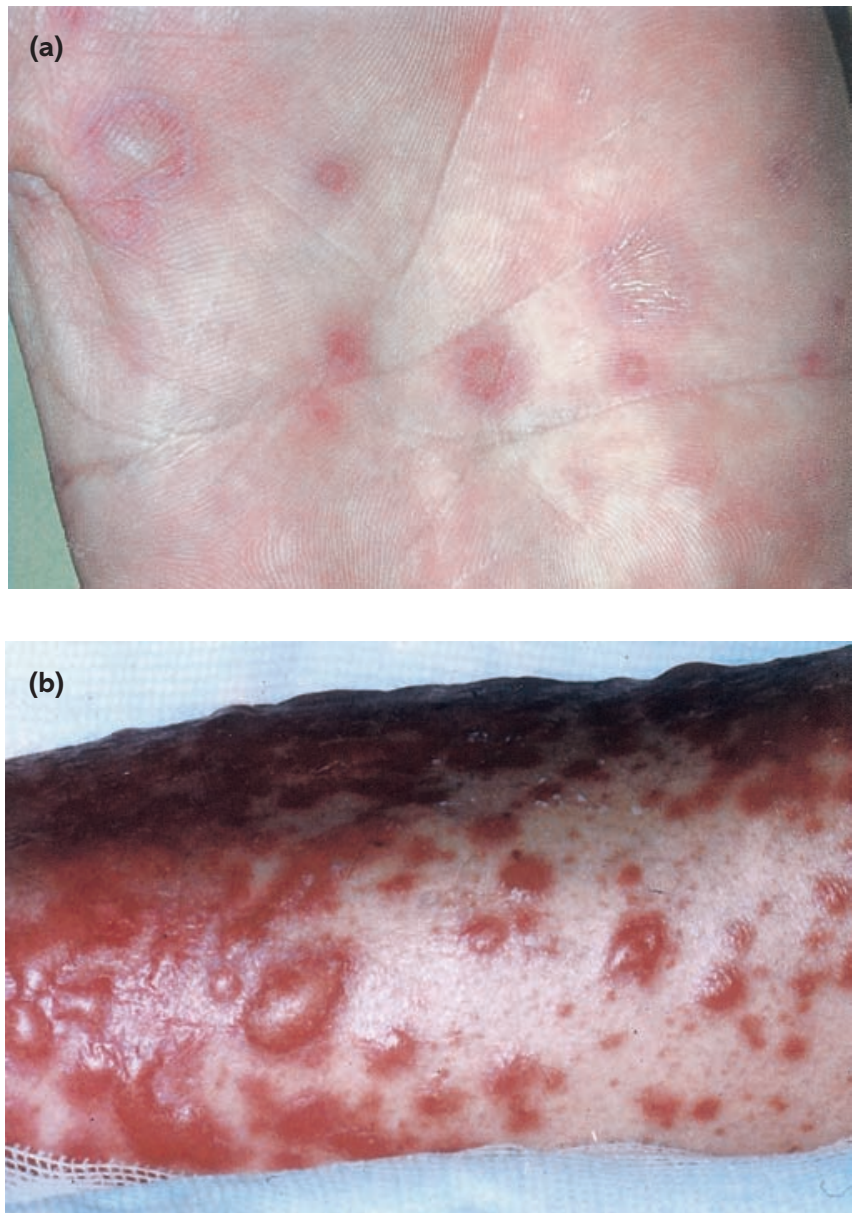

Fig 3. Target lesions: (a) typical three-zone target lesions on the hand in erythema multiforme; (b) atypical two-zone target lesions and haemorrhagic macules in toxic epidermal necrolysis.
It is also possible on clinical grounds to differentiate erythema multiforme (EM) with mucosal involvement (EM major), from SJS or TEN based upon the appearances of the initial lesions seen in these conditions (Figs 3(a), 3(b); Table 3). This has prognostic implications because EM is a relatively common eruption, most frequently caused by infection with herpes simplex virus.

\section{Diagnosis}

The diagnosis of established TEN and SIS can often be made clinically. The role of a skin biopsy and immunofluorescence is to exclude the main differential diagnoses, which include staphylococcal scalded skin syndrome, acute generalised exanthematous pustulosis, acute severe graft-versus-host disease and paraneoplastic pemphigus.

\section{Management}

Once the diagnosis is suspected, all potential causative drugs should be discontinued without delay, as this is one therapeutic manoeuvre that has been shown to improve prognosis. ${ }^{12}$ There is no definitive method of identifying the causative drug from a list of medications, so it is recommended that all drugs be stopped if possible. In general, medications initiated in the 3-4 weeks prior to the onset of symptoms are usually responsible. ${ }^{1}$

Patients should be transferred to a burns or high dependency unit where staff will be familiar with the complexities of managing patients with wide-

Table 3. Features of 'target' lesions* in erythema multiforme (EM), toxic epidermal necrolysis (TEN) and Stevens-Johnson syndrome (SJS).

$\begin{array}{ll}\text { EM } & 3 \text { zone iris or target lesion: } \\ & - \text { centre }=\text { dusky erythema/purpura/blister } \\ & \text { middle }=\text { oedema } \\ & \text { Acral distribution } \\ & 2 \text { zone atypical, targetoid lesions* or purpuric macules } \\ \text { Involve face/trunk/proximal limbs }\end{array}$

*A target lesion has the appearance of a dartboard bullseye, hence the name. It comprises three zones as indicated above. 'Targetoid' therefore refers to a lesion that may resemble the classical target lesion, however a targetoid lesion often comprises only two zones. 
Table 4. Signs of sepsis in toxic epidermal necrolysis and Stevens-Johnson syndrome patients.

- Temperature fluctuations (high or low)

- Rigors

- Hypotension

- Oliguria

- Reduced respiratory rate

- Labile glucose readings

- Reduced consciousness

spread epidermal loss. Supportive therapy is paramount and involves:

- Fluid and electrolyte balance, preferably via peripheral rather than central lines to reduce the risk of infection.

- Temperature regulation to minimise heat loss.

- Topical antiseptics to reduce skin colonisation with potential pathogenic organisms.

- Oral and nasal toilet: debris should be cleaned regularly and an antiseptic mouthwash used several times a day.

- Nutritional support. nasogastric feeding is often needed until the oral mucosa heals.

- Monitoring for signs of sepsis (Table 4): antibiotics should not be administered prophylactically as this encourages resistance.

- Pain relief: opiates are commonly required so patients need monitoring for signs of respiratory depression.

- Intubation and ventilation: if there is extensive epithelial necrosis of the airways, which may precipitate bronchial obstruction, or if signs of adult respiratory distress syndrome develop.

- Ophthalmological review should be sought urgently to minimise the risk of serious ocular sequelae, including conjunctival scarring and possible blindness. Antiseptic eye drops should be used frequently and any synechiae which have formed separated.

Table 5.

(a) The SCORTEN scoring system.

\section{SCORTEN variables}

- Extent of epidermal detachment $>10 \%$

- Age $>40$ years

- History of malignancy

- Heart rate $>120 / \mathrm{min}$

- Urea $>10 \mathrm{mmol} / \mathrm{l}$

- Glucose $>14 \mathrm{mmol} / \mathrm{l}$

- Bicarbonate $<20 \mathrm{mmol} / \mathrm{l}$

(b) Predicting mortality in toxic epidermal necrolysis and Stevens-Johnson syndrome using the SCORTEN system. One point is scored for each variable present in the first 24 hours after admission.

\begin{tabular}{cc}
$\begin{array}{c}\text { SCORTEN } \\
\text { total }\end{array}$ & $\begin{array}{c}\text { Predicted mortality } \\
\text { rate }(\%)\end{array}$ \\
\hline $0-1$ & 3.2 \\
2 & 12.1 \\
3 & 35.3 \\
4 & 58.3 \\
$\geq 5$ & 90
\end{tabular}

\section{Therapeutic interventions}

As a consequence of the low incidence of TEN, data on the use of potential 'disease-modifying' therapies consist of case reports and small, uncontrolled series.

\section{Steroids}

To date, the use of systemic steroids remains controversial. Some suggest that high-dose steroids used early in the evolution of TEN and SJS can stabilise the condition by halting further epithelial loss. ${ }^{14,15}$ Others argue that steroids increase both morbidity and mortality as a consequence of the increased risk of sepsis. ${ }^{16,17}$ It is now generally accepted that steroids provide no benefit once extensive epidermal loss has taken place, but the controversy will persist until a randomised, controlled trial is undertaken specifically to answer this question.

\section{Other therapies}

Other treatments, including cyclosporin (3-4 mg/kg/day), ${ }^{18,19}$ cyclophosphamide (100-300 mg/day), ${ }^{20} \mathrm{~N}$-acetylcysteine
$(2 \mathrm{~g} / 6 \mathrm{hr})^{21}$ and plasmapheresis, ${ }^{22,23}$ have also been used with reported benefit. Antibodies present in pooled human intravenous immunoglobulin (IVIG) preparations block Fas-mediated keratinocyte apoptosis in vitro. There is some evidence that IVIG at $0.2-1 \mathrm{~g} / \mathrm{kg} /$ day may halt the progression of skin disease in TEN and improve prognosis ${ }^{24,25}$ although this is disputed. ${ }^{26}$

\section{Prognosis}

The mortality of TEN (30\%) is at least sixfold higher than SJS $(<5 \%) .^{27}$ The primary cause of death is infection (Staphylococcus aureus and Pseudomonas aeruginosa), and multi-organ failure is not uncommon. Recently, the SCORTEN grading system ${ }^{28}$ (severity-of-illness score for TEN) has been developed to predict outcome in TEN (Table 5(a) and $5(\mathrm{~b}))$.

Mucosal scarring is a significant risk for survivors. Almost 50\% may develop serious ocular complications which, in addition to those mentioned earlier, include:

- corneal pannus 
- conjunctival squamous metaplasia

- keratoconjunctivitis sicca

- symblepharon (adhesion of one or both eyelids to the eyeball)

- entropion

- trichiasis.

If the trachea, oesophagus or anal and genital mucosae are involved, strictures may develop. ${ }^{13}$ Shedding of the nails may result in permanent anonychia.

Patients should not be discharged from hospital without clear instructions to avoid the culprit drug and ideally all structurally related drugs. A 'MedicAlert' bracelet is advisable, stating the $\operatorname{drug}(\mathrm{s})$ to which the patient has reacted. Familial cases of TEN have been recorded; therefore it is worthwhile informing first-degree relatives of their increased risk of an adverse reaction to the same $\operatorname{drug}(\mathrm{s}) .^{29}$

\section{References}

1 Roujeau JC, Kelly JP, Naldi L, Rzany B et al. Medication use and the risk of Stevens-Johnson syndrome or toxic epidermal necrolysis. N Engl J Med 1995;333: 1600-7.

2 Roujeau JC, Guillaume JC, Fabre JP, Penso $\mathrm{D}$ et al. Toxic epidermal necrolysis (Lyell syndrome). Incidence and drug etiology in France, 1981-1985. Arch Dermatol 1990; 126:37-42.

3 Rzany B, Mockenhaupt M, Stocker U, Hamouda O, Schopf E. Incidence of Stevens-Johnson syndrome and toxic epidermal necrolysis in patients with the acquired immunodeficiency syndrome in Germany. Arch Dermatol 1993;129:1059.

4 Saiag P, Caumes E, Chosidow O, Revuz J, Roujeau JC. Drug-induced toxic epidermal necrolysis (Lyell syndrome) in patients infected with the human immunodeficiency virus. J Am Acad Dermatol 1992;26:567-74.

5 Roujeau JC, Huynh TN, Bracq C, Guillaume JC et al. Genetic susceptibility to toxic epidermal necrolysis. Arch Dermatol 1987;123: 1171-3.

6 Wolkenstein P, Charue D, Laurent P, Revuz J et al. Metabolic predisposition to cutaneous adverse drug reactions. Role in toxic epidermal necrolysis caused by sulfonamides and anticonvulsants. Arch Dermatol 1995; 131:544-51.

7 Revuz J, Penso D, Roujeau JC, Guillaume JC et al. Toxic epidermal necrolysis. Clinical findings and prognosis factors in 87 patients. Arch Dermatol 1987;123:1160-5.

8 Paul C, Wolkenstein P, Adle H, Wechsler J et al. Apoptosis as a mechanism of ker- atinocyte death in toxic epidermal necrolysis. Br J Dermatol 1996;134:710-4.

9 Rhodes LE, Hashim IA, McLaughlin PJ, Friedmann PS. Blister fluid cytokines in cutaneous inflammatory bullous disorders. Acta Derm Venereol 1999;79:288-90.

10 Paquet P, Nikkels A, Arrese JE, Vanderkelen A, Pierard GE. Macrophages and tumour necrosis factor alpha in toxic epidermal necrolysis. Arch Dermatol 1994;130:605-8.

11 Wehrli P, Viard I, Bullani R, Tschopp J, French LE. Death receptors in cutaneous biology and disease. Review. J Invest Dermatol 2000;115:141-8.

12 Garcia-Doval I, LeCleach L, Bocquet H, Otero XL, Roujeau JC. Toxic epidermal necrolysis and Stevens-Johnson syndrome: does early withdrawal of causative drugs decrease the risk of death? Arch Dermatol 2000;136:323-7.

13 Roujeau JC, Chosidow O, Saiag P, Guillaume JC. Toxic epidermal necrolysis (Lyell syndrome). Review. J Am Acad Dermatol 1990;23(6 Pt 1):1039-58.

14 Stables GI, Lever RS. Toxic epidermal necrolysis and systemic corticosteroids. $\mathrm{Br} J$ Dermatol 1993;128:357.

15 Martinez AE, Atherton DJ. High-dose systemic corticosteroids can arrest recurrences of severe mucocutaneous erythema multiforme. Paediatr Dermatol 2000;17:87-90.

16 Halebian PH, Corder VJ, Madden MR, Finklestein JL, Shires GT. Improved burn center survival of patients with toxic epidermal necrolysis managed without corticosteroids. Ann Surg 1986;205:503-12.

17 Rasmussen JE. Erythema multiforme in children. Response to treatment with systemic corticosteroids. Br J Dermatol 1976; 95:181-6.

18 Hewitt J, Ormerod AD. Toxic epidermal necrolysis treated with cyclosporin. Clin Exp Dermatol 1992;17:264-5.

19 Arévalo JM, Lorente JA, Gonzéles-Herrada C, Jiménez-Reyes J. Treatment of toxic epidermal necrolysis with cyclosporin A. J Trauma 2000;48:473-8.

20 Heng MC, Allen SG. Efficacy of cyclophosphamide in toxic epidermal necrolysis. J Am Acad Dermatol 1991;25(5 Pt 1):778-86.

21 Redondo P, de Felipe I, de la Pena A, Aramendia JM, Vanaclocha V. Druginduced hypersensitivity syndrome and toxic epidermal necrolysis. Treatment with N-acetylcysteine. Br J Dermatol 1997; 136:645-6.

22 Kamanabroo D, Schmitz-Landgraf W, Czarnetzki BM. Plasmapheresis in severe drug-induced toxic epidermal necrolysis. Arch Dermatol 1985;121:1548-9.

23 Egan CA, Grant WJ, Morris SE, Saffle JR, Zone JJ. Plasmapheresis as an adjunct treatment in toxic epidermal necrolysis. $J \mathrm{Am}$ Acad Dermatol 1999;40:458-61.

24 Viard I, Wehrli P, Bullani R, Schneider P et al. Inhibition of toxic epidermal necrolysis by blockade of CD95 with human intra- venous immunoglobulin. Science 1998;282: 490-3.

25 Prins C, Kerdel FA, Padilla RS, Hunziker T et al. Treatment of toxic epidermal necrolysis with high-dose intravenous immunoglobulins: multicenter retrospective analysis of 48 consecutive cases. Arch Dermatol 2003;139:26-32.

26 Bachot N, Revuz J, Roujeau JC. Intravenous immunoglobulin treatment for StevensJohnson syndrome and toxic epidermal necrolysis: a prospective noncomparative study showing no benefit on mortality or progression. Arch Dermatol 2003;139:33-6.

27 Roujeau JC, Stern RS. Severe adverse cutaneous reactions to drugs. Review. N Engl J Med 1994;331:1272-85.

28 Bastuji-Garin S, Fouchard N, Bertocchi M, Roujeau JC et al. SCORTEN: a severityof-illness score for toxic epidermal necrolysis. J Invest Dermatol 2000;115:149-53.

29 Fischer PR, Shigeoka AO. Familial occurrence of Stevens-Johnson syndrome. Am J Dis Child 1983;137:914-6. 